УДК 340.123

\author{
H.К. Тарасов \\ адъюнкт \\ Санкт-Петербургский университет МВД России \\ Российская Федерачия, 198206, г. Санкт-Петербург, ул. Лётчика Пилютова, д. 1 \\ ORCID: 0000-0002-0192-0904. E-mail: nicrosoft@mail.ru

\section{Проблемы применения государственного принуждения в трактовке отечественных юристов конца XIX - начала XX века}

\begin{abstract}
Аннотация: В статье рассматриваются вопросы, касающиеся трактовки российскими юристами конца XIX - начала XX в. роли государственного принуждения в обеспечении законности. Подчеркивается взаимосвязь между состоянием законности и качественными характеристиками государственного принуждения. Обращено внимание на проблему государственного принуждения в правореализационном и доктринальном аспектах. Акцентировано внимание на развитии мысли о природе, предназначении и пределах государственного принуждения в отечественной полицейско-правовой теории конца XIX - начала XX вв. Сделан вывод о том, что правоведами государственное принуждение рассматривалось как исключительное, крайнее средство, использование и применение которого допустимо только на основе правовых норм в целях обеспечения безопасности и стабильности его общественно-политической и политико-правовой системы, соблюдения режима законности.

Ключевые слова: правовое государство, полицейское государство, полицейское право, законность, государственное принуждение, правовое принуждение, государственно-правовые учения, российские полицеисты.
\end{abstract}

Для цитирования: Тарасов Н. К. Проблемы применения государственного принуждения в трактовке отечественных юристов конца XIX - начала XX века // Вестник Санкт-Петербургского университета МВД России. - 2019. - № 2 (82). - С. 96-105. DOI: 10.35750/2071-8284-2019-2-96-105.

Nikita K. Tarasov

Graduate

Saint-Petersburg University of the MIA of Russia

1, Letchika Pilyutova str., St. Petersburg, 198206, Russian Federation

ORCID: 0000-0002-0192-0904. E-mail: nicrosoft@mail.ru

\title{
Problems of application of state coercion in the interpretation of local lawyers in the late XIX - early XX century
}

Annotation: The questions relating to the interpretation of the Russian lawyers of the late XIX early XX century of the role of state compulsion in ensuring the rule of law are considered in article. The interrelation between the state of legality and qualitative characteristics of state coercion is emphasized. The author draws attention to the problem of state coercion in the legal and doctrinal 
aspects. His attention focuses on the development of the idea of the nature, purpose and limits of state coercion in the domestic police-legal theory of the late XIX - early XX century. The author considers that legal scholars thought of state coercion as an exclusive, extreme means, the use and application of which is permissible only on the basis of legal norms in order to ensure the security and stability of its socio-political and political-legal system, in compliance with the rule of law.

Keywords: legal state, police state, police law, legality, state coercion, legal coercion, state legal theories, Russian police scientists

For citation: Tarasov N. K. Problems of application of state coercion in the interpretation of local lawyers in the late XIX - early XX century // Vestnik of St. Petersburg University of the Ministry of Internal Affairs of Russia. - 2019. - № 2 (82). - P. 96-105. DOI: 10.35750/2071-82842019-2-96-105.

Соблюдать конституциюи законы - обязанность каждого гражданина любой страны. Конституция Российской Федерации (ч. 2 ст. 15) возлагает такую обязанность на различные субъекты, подчеркивая, что «органы государственной власти, органы местного самоуправления, должностные лица, граждане и их объединения обязаны соблюдать Конституцию Российской Федерации и законы» Российской Федерации. Однако, по данным Генеральной прокуратуры Российской Федерации, только за январь-март 2019 г. в сфере надзора за исполнением законов, соблюдением прав и свобод человека и гражданина выявлено 1160665 нарушений закона (аналогичный период прошлого года (далее - АППГ) - 1131941), в сфере надзора за исполнением законов на досудебной стадии уголовного судопроизводства - 1294374 $(\text { АППГ - 1281903) })^{1}$. За этот же период на территории России зарегистрировано 490920 преступлений (АППГ - на 1,6 \% меньше) ${ }^{2}$. Эти цифры свидетельствуют о том, что режим соблюдения законности, предписанный ч. 2 ст. 15 Конституции Российской Федерации, в настоящее время не достигнут,

\footnotetext{
${ }^{1}$ Статистические данные об основных показателях деятельности органов прокуратуры Российской Федерации за январь-март 2019 г. // Генеральная прокуратура Российской Федерации: официальный сайт. - Режим доступа: http:/genproc.gov.ru/stat/ data/1599656 (дата обращения: 15.05.2019).

${ }^{2}$ Состояние преступности в России за март 2019 г. : статистический сборник // Генеральная прокуратура Российской Федерации: официальный сайт. - Режим доступа: http:/genproc.gov.ru/upload/iblock/ d6d/sbornik_3_2019.pdf (дата обращения: 15.05.2019).
}

и вопросы, касающиеся путей и способов эффективного обеспечения законности и укрепления правопорядка, до сих пор не получили своего решения.

Фактором, оказывающим воздействие на выработку оптимальной модели обеспечения законности в современной России, выступает нерешённость отдельных вопросов в теоретической юриспруденции, которая, как подчеркивает Н. С. Нижник, обусловлена тем, что «единый подход к пониманию принципов, требований, гарантий законности отсутствует, особенности функционирования механизма обеспечения законности в российском государстве выявлены не в полном объёме» $[11$, с. 226$]$.

В современной юридической науке законность рассматривается как многоаспектное политико-правовое явление, оценка содержания и характеристик которого в контексте различных типов правопонимания дается по-разному [9, с. 30-34]. Несмотря на плюрализм подходов, учёные в целом единодушно выделяют сущностную характеристику законности - точное и неуклонное соблюдение законодательства [9, c. 30-34]. Практическая реализация данного требования зависит от наличия соответствующих гарантий законности, то есть объективных условий, способствующих обеспечению законности, субъективных факторов, оказывающих влияние на данный процесс, а также используемых специальных средств и методов организационноправового характера.

В качестве средства и гарантии обеспечения законности государство легально 
использует принуждение [3, с. 25-30; 12, с. $114-115 ; 6$, с. 59]. В современных реалиях цели, основания, критерии допустимости государственного принуждения как средства и гарантии обеспечения законности детерминированы рядом обстоятельств. Во-первых, в условиях построения правового государства права и свободы человека и гражданина, неприкосновенность личности выступают реперными точками, на основе которых развертывается вся правовая политика, направленная главным образом на достижение разумного баланса интересов государства, общества и личности и выработку оптимальной модели сочетания гарантий прав личности и возможности решения общегосударственных задач [8, с. 239-250]. Во-вторых, государственное принуждение является фактором, который ограничивает свободу принуждаемого лица [14, с. 62-66], выступая тем самым, с одной стороны, средством для обеспечения прав и свобод личности, а с другой стороны, средством, позволяющим эти права и свободы ограничивать. Поэтому параметры государственного принуждения тесно связаны с вопросами его легитимации [2, с. 71].

На уровень социальной справедливости в обществе оказывает влияние не столько количество применения государством мер принуждения, сколько его качественные характеристики (цели, основания, соразмерность социальной опасности). Все неправовое, подчёркивал И. Кант, наносит ущерб праву, поэтому в отношении тех, кто препятствует свободе или оказывает ей сопротивление, государство правомочно применять принуждение 3 . Важными проблемами остаются реализация мер государственного принуждения в современных условиях и осмысление накопленного в этой сфере общественных отношений опыта. Н. B. Макарейко полагает, что до настоящего времени не осуществлены в должной мере исследования государственного принуждения в доктринальном аспекте: мало изучены меры предупреждения, пресечения, за-

\footnotetext{
${ }^{3}$ Кант И. Собрание сочинений : В 8 т. - Т. 6. Москва: Чоро, 1994. - С. 254-255.
}

щиты; не охарактеризованы новые формы принуждения (муниципально-правовое, таможенно-правовое, финансово-правовое и др.) ${ }^{4}$. «Наряду с необоснованным, а зачастую незаконным применением государственного принуждения, - констатирует Н. В. Макарейко, - имеют место факты псевдогуманности, когда при наличии соответствующих оснований органы государственной власти допускают бездействие, отказываются от применения мер государственного принуждения» ${ }^{5}$.

Комплексная характеристика содержания государственного принуждения в контексте обеспечения законности, ретроспективный анализ практики применения мер государственного принуждения, изучение теоретико-правовых сторон его функционирования могут способствовать определению путей и средств развития в России эффективного государственного управления, согласованного с принципами правового государства. Решение этой задачи невозможно без учёта правовых традиций, специфики отечественного правосознания, правовой культуры и опыта теоретико-правового конструирования, накопленного отечественной юриспруденцией.

Теоретико-правовые проблемы, касающиеся государственного принуждения, становились предметом осмысления российских учёных. Отечественные мыслители И. Е. Андреевский, В. Ф. Дерюжинский, В. А. Гаген, И. Т. Тарасов, А. А. Трифонов, В. В. Ивановский, В. М. Гессен, Э. Н. Берендтс, А. И. Елистратов серьезное внимание уделяли вопросам, имевшим не только высокую теоретическую, но и практическую значимость в конце XIX - начале XX вв.: назначению государственного принуждения в системе государственного управления; соотношению методов убеждения и принуждения при реализации государственной власти; соответствию мер государственного при-

${ }^{4}$ Макарейко Н. В. Государственное принуждение в механизме обеспечения экономической безопасности: теоретические и прикладные проблемы : дис. ... д-ра юрид. наук: 12.00.01 / Макарейко Николай Владимирович. - Н. Новгород, 2016. - С. 7.

${ }^{5}$ Там же. - С. 6. 
нуждения целям защиты государственных, общественных и частных интересов. Высокий уровень социальной напряжённости (развитие революционно-демократических движений, активизация революционных кружков и организаций, обострение криминальной обстановки, созревание революционной ситуации и др.) актуализировал изучение сущности и проблем применения мер государственного принуждения.

Предупреждение и разрешение социальных конфликтов в условиях революционных ситуаций требовало выполнения нескольких условий: сохранения приемлемого качества государственного управления, способного обеспечить целостность и стабильность государственности, а также пересмотра базовых положений законодательства в социальной сфере, направленных на устранение социально-классовых противоречий. Государственное управление должно было, с одной стороны, обеспечить условия для социальных преобразований, создать ситуацию, исключающую либо купирующую деструктивные факторы (угрозы государственному строю, чрезвычайные ситуаций и т. д.), а с другой - произвести позитивные социальные преобразования, используя широкий круг организационно-правовых мер, в том числе и мер государственного принуждения.

В начале XX в. либеральный подход к решению социально значимых вопросов набирал силу и детерминировал постепенные изменения в системе государственного управления. Указ от 12 декабря 1904 г. «О предначертаниях к усовершенствованию государственного порядка» ${ }^{6}$, Манифест 17 октября 1905 г. «Об усовершенствовании государственного порядка» ${ }^{7}$ юридически закрепили основы гражданской свободы на началах неприкосновенности личности, свободы совести, слова, собраний и союзов,

${ }^{6} \mathrm{O}$ предначертаниях к усовершенствованию государственного порядка. 12 декабря 1904 г. // Полное собрание законов Российской империи. - Собрание 3-е. - T. XXIV. - № 25495. - Санкт-Петербург, 1907.

${ }^{7}$ Об усовершенствовании государственного порядка. 17 октября 1905 г. // Полное собрание законов Российской империи. - Собрание 3-е. - T. XXV. № 26803. - Санкт-Петербург, 1908. что повлекло за собой изменения во взаимоотношениях власти и общества, в перспективах использования государством мер принуждения.

Общее понимание сущности принуждения среди ученых-правоведов конца XIX - начала XX в. выражалось главным образом как вторжение в свободу воли индивида, ограничение его прав путём непосредственного физического насилия либо угроз.

Как принуждение должно рассматриваться любое воздействие на несовпадающую волю, полагал Н. Н. Алексеев ${ }^{8}$. Два аспекта принуждения - физическое насилие и устрашающее воздействие на человеческую волю (психическое принуждение) рассматривал Е. Н. Трубецкой ${ }^{9}$.

Рассуждая о взаимосвязях права и принуждения, Н. А. Гредескул подчеркивал, что «основную свою работу в пользу права физическое насилие совершает в состоянии угрозы, то есть как орудие психологического воздействия на граждан, а не в том грубом виде, какой оно имеет само по себе» ${ }^{10}$. Значение принуждения в праве - подчиненное, а не первостепенное. Не принуждение как таковое и непосредственное дает праву осуществление, а только повиновение граждан $^{11}$ - сознательное принятие ими установленных норм.

«Право... иногда допускает и принуждение, - рассуждал Н. М. Коркунов, - а именно, в тех случаях, когда разграничение интересов достигается посредством одного запрещения действий, мешающих осуществлению разграниченных интересов» ${ }^{12}$. Пра-

${ }^{8}$ Алексеев Н. Н. Основы философии права. - СПб Алексеев Н. Н. Основы философии права. Санкт-Петербург: Изд-во С.-Петербург. юрид. ин-та, 1998. - C. 179.

9 Трубецкой Е. Н. Лекции по энциклопедии права. - Москва: Т-во типографии А. И. Мамонтова, 1917. - C. 18.

${ }^{10}$ Гредескул Н. А. К учению об осуществлении права. Интеллектуальный процесс, требующийся для осуществления права. - Харьков: Типография Адольфа Дарре, 1900. - С. 28.

${ }^{11}$ Там же.

${ }^{12}$ Коркунов Н. М. Лекции по общей теории права. 8-е изд. - Санкт-Петербург: Изд. юрид. кн. магазина Н.К. Мартынова, 1908. - С. 40. 
во выступает как «обеспечение жизненных условий общества в форме принуждения», «система социальных целей, гарантируемых принуждением», утверждал Л. И. Петражицкий ${ }^{13}$.

Сущность государственного принуждения и проблемы его применения в российском государстве являлись предметом осмысления учёных-полицеистов.

Ректор Императорского СанктПетербургского университета профессор И. Е. Андреевский признавал за каждым человеком право на личную свободу деятельности и считал не просто излишним, но и вредным, ограничивать её со стороны государства, если такое ограничение вытекает не из стремления обеспечить благосостояние и безопасность. Формула, которая выступала критерием допустимости вмешательства органов государства в частную сферу, определялась положением «коренного» закона: «Во всех случаях, когда отдельное лицо собственными силами и средствами не может создать таких условий безопасности и благосостояния, без которых развитие его невозможно, на помощь ему должна явиться деятельность других, называемых полицейской» ${ }^{14}$. Андреевский связывал государственное принуждение с «отрицательной полицейской деятельностью» государства и отождествлял его с полицейским принуждением. По Андреевскому, сущность полицейского принуждения заключалась в устранении причин и условий, нарушающих безопасность отдельного лица, общества или государства; противодействии «злой воле» людей, которые попирают права других лиц; противодействии угрозам, проистекающим из природы человека, не связанных со «злой волей» ${ }^{15}$. «Не подлежит сомнению, - констатировал Андреевский, что и при наивыгоднейших условиях госу-

13 Петражицкий Л. И. Теория права и государства в связи с теорией нравственности / 2-е изд.: испр. и доп. - Т. 1-2. - Санкт-Петербург: Тип. М. Меркушева, Тип. т-ва «Екатерингоф. печ. дело», 1909. - С. 260.

${ }^{14}$ Андреевский И.Е. Полицейское право: Введение и ч. 1. Полиция безопасности. - Т. 1 / 2-е изд., испр. и доп. - Санкт-Петербург: Тип. Э. Праца, 1874. - C. 17.

${ }^{15}$ Там же. дарственной жизни всегда будут личности, готовые ниспровергнуть права других, и, следовательно, всегда придётся изыскивать предупредительные меры» ${ }^{16}$. В круг последних входили: наблюдение за общественными союзами и ассоциациями, пресечение «восстаний», «возмущений», «расхищения государственной собственности» и др.

Декан юридического факультета Императорского Московского университета профессор И. Т. Тарасов, характеризуя полицейское принуждение, рассматривал его в контексте проблем функционирования институтов исполнительной власти $[13$, с. $74-75]$. Он подчёркивал, что в целях реализации законов, действующих в государстве, должностные лица органов исполнительной власти должны быть наделены соответствующими полномочиями, в том числе и правом применять меры принуждения [4, с. 25]. Принуждение - деятельность по устранению сопротивления, с которым сталкивается администрация в процессе исполнения предусмотренных законом задач $^{17}$. Граница принуждения, подчеркивал И. Т. Тарасов, определяется родом и степенью сопротивления, а не значимостью цели деятельности, поэтому принуждение применяется с момента возникновения сопротивления и прекращается с момента прекращения сопротивления [1, с. 92]. Принуждение, по мнению И. Т. Тарасова, должно рассматриваться как крайняя мера, так как именно принуждением наиболее легко и часто могут быть нарушены права граждан, а поэтому применение принудительных мер должно осуществляться исключительно на правовой основе [13, с. 75].

Профессор Императорского Казанского университета В. В. Ивановский среди всех задач государства выделял две ключевые и взаимообусловленные: обеспечение безопасности и обеспечение благосостояния граждан. «Государство при помощи всех находящихся в его обладании средств и

\footnotetext{
${ }^{16}$ Там же. - С. 2.
}

17 Тарасов И. Т. Лекции по полицейскому (административному) праву. Т. 2. Общая часть. - Москва: Тип. Моск. ун-та, 1910. - С. 67. 
способов приходит на помощь частным лицам в деле достижения ими возможно высшей ступени благосостояния», подчеркивал Ивановский ${ }^{18}$. Благосостояние - это удовлетворение всех физических и духовных потребностей человека $[13$, с. 79], важнейшей среди которых является потребность в безопасности [10, с. 81-82]. Удовлетворение потребности в безопасности обусловливает функционирование полиции - принудительную деятельность государства в сфере внутреннего управления [13, с. 79]. Принимая во внимание то, что сущность принудительной деятельности проявляется в борьбе с опасностями, стоящими на пути к благосостоянию, В.В.Ивановский выделял две области государственной деятельности - полиция безопасности (в рамках которой находит применение принуждение) и полиция благосостояния (чуждая всякого рода принуждению) [10, с. 72-74]. В области полиции безопасности меры принуждения более всего затрагивают права и свободы человеческой личности ${ }^{19}$. В. В. Ивановский, как и И. Т. Тарасов, обращал внимание на необходимость определения границ принудительной деятельности: принуждение должно применяться в случаях сопротивления законному требованию; применение принуждения должно быть прямо пропорционально возрастанию сопротивления и должно соответствовать степени и силе сопротивления. Обязательность законодательного закрепления всех форм принуждения в целях недопущения произвола и широкого личного усмотрения государственных органов Ивановский считал необходимой [13, с. 80].

Государственный и политический деятель профессор В. М. Гессен связывал принудительную деятельность государства с необходимостью обеспечения исполнения законов [5, с. 87-95]. Исполнительная функция правительства, полагал Гессен, реализуется в двух формах, в зависимости от того,

${ }^{19}$ Ивановский В. В. Учебник административного права (полицейское право; право внутреннего управления). - Казань: Типо-литография Императорского университета, 1908. - С. 78. на ком лежит обязанность непосредственного исполнения закона, - на органах администрации или на самих гражданах ${ }^{20}$. В первом случае, к гражданам со стороны органов администрации не могут быть предъявлены требования, обязательные для исполнения. Поэтому выполнение требований закона самой администрацией возможно лишь на паритетных началах с гражданами, то есть путём заключения с ними частноправовых сделок по оказанию каких-либо услуг для администрации. Во втором случае, когда исполнение закона от граждан требует либо определенных действий, либо воздержания от их совершения, исполнительная функция может реализоваться и в виде принуждения граждан к исполнению закона. Администрация в таком случае наделяется принудительной властью, осуществление которой определяется соответствующими нормами права. Нормы, регулирующие осуществление принудительной власти, - это нормы полицейского права, подчеркивал Гессен ${ }^{21}$, а «полицейское право правового государства - это наука о нормах, регулирующих применение государственной принудительной власти» ${ }^{22}$. В. М. Гессен разделял принудительные полномочия администрации на две категории: нормальные полномочия (которые реализуются в «нормальных условиях государственной и общественной жизни» ${ }^{23}$ ) и чрезвычайные полномочия (которые используются только «в условиях государственной и общественной жизни, по тем или иным причинам исключительным» ${ }^{24}$ ). В массе мер принуждения Гессен выделял меры непосредственного принуждения, репрессивно-принудительные меры, превентивно или предупредительно-принудительные меры ${ }^{25}$.

${ }^{20}$ Гессен В. М. Лекции по полицейскому праву. - Санкт-Петербург: Типография «Север», 1907-1908. - C. 48.

${ }^{21}$ Там же.

${ }^{22}$ Гессен В. М. Из лекций по полицейскому праву, читанных в 1901-1902 учебном году в Александровской военно-юридической Академии. - СанктПетербург: Типо-лит. М. Гинсбурга, 1902. - С. 13.

${ }^{23}$ Гессен В. М. Лекции по полицейскому праву. Санкт-Петербург, 1907-1908. - С. 49.

${ }^{24}$ Там же.

${ }^{25}$ Там же. 
Отечественный правовед В. Ф. Дерюжинский, анализируя деятельность государства в контексте реализации субъективных прав граждан ${ }^{26}$, констатировал, что государство, охраняя право на свободу передвижения (субъективное право), следит за его реализацией, в случае наступления определённых обстоятельств (необходимость задержания лица, подозреваемого в совершении правонарушения; обязанность не покидать данный район вследствие подписки о невыезде и т.п.) ${ }^{27}$. «Принудительная власть, применяемая государственными органами, - подчёркивал Дерюжинский, - это не вещь в себе и для себя, она существует для того, чтобы обеспечивать права и свободы граждан» ${ }^{28}$.

Вклад в развитие представлений о природе государственного принуждения внёс видный российский ученый Э. Н. Берендтс. Он считал, что в основе правоотношений гражданина и государства лежит соглашение, в соответствии с которым государство устанавливает общеобязательные правила поведения, а гражданин обязан этим правилам подчиняться. При этом на государство возлагается обязанность соблюдать и защищать права и свободы человека и гражданина, а гражданин вправе требовать от государства исполнения этой обязанности [7, c. 149-161]. Необходимо достигать такого соглашения, полагал Берендтс, при котором произвол или необоснованное превышение прав одного из субъектов были бы исключены [7, с. 149-161]. Меры государственного принуждения могут использоваться и в правовом государстве с целью выполнения его властных предписаний в отношении индивида [7, с. 149-161].

Таким образом, в конце XIX - начале XX в. феномен «государственное принуждение»

${ }^{26}$ Дерюжинский В. Ф. Полицейское право. Пособие для студентов. 4-е изд. - Петроград: Сенат. тип., 1917. - С. 1.

${ }^{27}$ Там же.

${ }^{28}$ Бельский К. С. Дерюжинский Владимир Федорович // Правовая наука и юридическая идеология России. Энциклопедический словарь биографий / отв. ред. В. М. Сырых. - Москва: Российская академия правосудия, 2009. - С. 205. привлекал внимание и государственных деятелей, и учёных. Острый интерес российских юристов, прежде всего развивающих полицейско-правовую теорию, к природе и проблемам применения мер государственного принуждения был обусловлен главным образом сложной социально-политической обстановкой, которая сложилась в России в конце XIX - начале XX вв. [15, с. 222-228]. Перед юридической наукой встала серьёзная задача - осмыслить роль и место государственного принуждения в системе государственного управления, сформулировать принципы его применения. Особый вклад в разработку данной проблематики внесли учёные-полицеисты: И. Е. Андреевский, И. Т. Тарасов, В. В. Ивановский В. Ф. Дерюжинский, В. М. Гессен, Э. Н. Берендтс. Учёные обращали внимание на опасность превращения государственного принуждения в произвольное насилие над личностью, на угрозу нарушения мерами государственного принуждения прав и свобод человека, поэтому рассматривали его как исключительное, крайнее средство, использование и применение которого допустимо только на основе правовых норм в целях обеспечения безопасности и стабильности его общественнополитической и политико-правовой системы, соблюдения режима законности.

Отечественные полицеисты в конце XIX - начале XX вв. выделили принципы применения мер государственного принуждения, в числе которых следующие:

- государственное принуждение может быть использовано только при условии опоры на базовый принцип признания прав и свобод человека как наивысшей ценности и принцип неприкосновенности личности;

- государственное принуждение может быть применено только в случаях сопротивления законным требованиям государства;

- сила и интенсивность принуждения должно быть прямо пропорционально возрастанию сопротивления и должно соответствовать степени и силе сопротивления;

- любая мера государственного принуждения должна быть законодательно закреплена, а порядок его применения - чётко регламентирован. 
Идеи, высказанные учёными-полицеистами в конце XIX - начале XX вв., нашли своё отражение в современном законодательстве Российской Федерации ${ }^{29}$. Однако до настоящего времени конституционная норма, предписывающая соблюдать законодательство Российской Федерации, в полном объёме не реализуется. Одним из инструментов, позволяющим добиваться выполнения указанной нормы, является государственное принуждение. Но этот инструмент и сам сегодня нуждается в совершенствовании, в приведении его в состояние, адекватное реалиям XXI века.

\section{Список литературь}

1. Аврутин Ю. Е. Истоки формирования института полиции и полицейского права // Полицейское право. - 2005. - № 1. - С. 88-95.

2. Балахонский В. В. Феномен «государственное принуждение»: философско-правовой анализ / Российская полиция: три века служения Отечеству [Электронный ресурс] : материалы юбилейной Международной научной конференции, посвящённой 300-летию российской полиции. Санкт-Петербург, 23-25 апреля 2018 г. / под ред. Н. С. Нижник. - Электронные дан. (19,6 Мб). - Санкт-Петербург: Санкт-Петербургский университет МВД России, 2018. - C. 71-74.

3. Вершинина С. И. О теории принуждения в правовой науке // Вектор науки Тольяттинского государственного университета. - 2009. - № 2 (5).- С. 25-30.

4. Егоров Н. Ю. Проблемы применения административного принуждения в России в теоретическом наследии И. Т. Тарасова / Государство и право в изменяющемся мире : материалы Международной научно-практической конференции, Н. Новгород, 5 марта 2015 г. - Н. Новгород: РГУП, 2016. - С. 24-28.

5. Козинникова Е. Н. Исключительное положение как чрезвычайный правовой режим (опыт анализа нормативных актов и работ полицеистов Российской империи конца XIX начала XX века) // Genesis: исторические исследования. - 2017. - № 11. - C. 87-95. - DOI: 10.25136/2409-868X.2017.11.22543. - URL: http://e-notabene.ru/hr/article_22543.html (дата обращения: 16.05.2019).

6. Засовенко А. Ю. Законность - основа правоприменительной деятельности российской полиции / Государство и право: эволюция, современное состояние, перспективы развития (навстречу 300-летию полиции) : материалы XIV Международной научно-теоретической конференции. Санкт-Петербург, 27-28 апреля 2017 г. / под ред. Н. С. Нижник: В 2 т. - Т. II. - Санкт-Петербург: Изд-во СПб ун-та МВД России, 2017. - С. 59-61.

7. Никифорова С. А. Э. Н. Берендтс о статусе полиции в полицейском и правовом государстве // Genesis: исторические исследования. - 2016. - № 6. - C. 149-161. - DOI: 10.7256/2409-868X.2016.6.21066. - URL: http://e-notabene.ru/hr/article_21066.html (дата обращения: 16.05.2019).

8. Нижник Н. С. Взаимоотношения власти, общества и личности как предмет полицейско-правовой теории / Российская полиция: три века служения Отечеству [Электронный ресурс] : материалы юбилейной Международной научной конференции, посвящённой 300-летию российской полиции. Санкт-Петербург, 23-25 апреля 2018 г. / под ред. Н. С. Нижник. Электронные дан. (19,6 Мб). - Санкт-Петербург: Санкт-Петербургский университет МВД России, 2018. - С. 239-250.

9. Нижник Н. С. Законность: плюрализм подходов к рассмотрению социоюридического феномена в современной юридической науке // Вестник Кыргызско-Российского славянского университета. - 2014. - Т 14. - № 12. - С. 30-34.

10. Нижник Н. С. Омнипотенция полицейского государства в оценке российской полицеистики // Genesis: исторические исследования. - 2017. - № 11. - C. 67-86.

11. Нижник Н. С. Социоюридический феномен «законность» в условиях диалога научных парадигм в современной юриспруденции // Проблемы права. - 2012. - № 3. - С. 226-231. 
12. Нижник Н. С., Папьрин В. В. Законность как социоюридический феномен. - СанктПетербург: Санкт-Петербургский университет Государственной противопожарной службы МЧС России: Астерион, 2012. - 190 с.

13. Нижник Н. С., Дергилёва С. Ю. Государство и право в теоретико-правовых воззрениях А. И. Елистратова : монография. - Москва: Юрлитинформ, 2017. - 376 с.

14. Тарасов Н. К. Государственное принуждение: плюрализм подходов к определению сущности / Актуальные проблемы права и правоприменительной деятельности: Материалы Всероссийской научно-практической конференции (18 мая 2018 г.) / ред. кол.: Ю. В. Сапронов, Т. Ю. Пантелеева Н. В. Винникова, А. С. Пеструилов, К. С. Смирнова, Л. Г. Литвяк, В. М. Палий, М. Р. Кангезов. - Краснодар: Краснодарский университет МВД России, 2018. - С. 62-66.

15. Тарасов Н. К. О детерминантах обоснования применения мер государственного принуждения полицейско-правовой теорией России в конце XIX - начале XX века // Труды Академии МВД Республики Таджикистан. - 2019. - № 1 (41). - С. 222-228.

\section{References}

1. Avrutin Yu. E. Istoki formirovaniya instituta politsii i politseiskogo prava // Politseiskoe pravo. - 2005. - № 1. - S. 88-95.

2. Balakhonskiy V. V. Fenomen «gosudarstvennoye prinuzhdeniye»: filosofsko-pravovoy analiz / Rossiyskaya politsiya: tri veka sluzheniya Otechestvu [Elektronnyy resurs] : materialy yubileynoy Mezhdunarodnoy nauchnoy konferentsii, posvyashchonnoy 300-letiyu rossiyskoy politsii. SanktPeterburg, 23-25 aprelya 2018 g. / pod red. N. S. Nizhnik. - Elektronnyye dan. (19,6 Mb). - SanktPeterburg: Sankt-Peterburgskiy universitet MVD Rossii, 2018. - S. 71-74.

3. Vershinina S. I. O teorii prinuzhdeniya v pravovoy nauke // Vektor nauki Tol'yattinskogo gosudarstvennogo universiteta. - 2009. - № 2 (5).- S. 25-30.

4. Yegorov $N$. Yu. Problemy primeneniya administrativnogo prinuzhdeniya $\mathrm{v}$ Rossii $\mathrm{v}$ teoreticheskom nasledii I. T. Tarasova / Gosudarstvo i pravo v izmenyayushchemsya mire : materialy Mezhdunarodnoy nauchno-prakticheskoy konferentsii, N. Novgorod, 5 marta 2015 g. N. Novgorod: RGUP, 2016. - S. 24-28.

5. Kozinnikova Ye. N. Isklyuchitel'noye polozheniye kak chrezvychaynyy pravovoy rezhim (opyt analiza normativnykh aktov i rabot politseistov Rossiyskoy imperii kontsa XIX - nachala XX veka) // Genesis: istoricheskiye issledovaniya. - 2017. - № 11. - S. 87-95. - DOI: 10.25136/2409868X.2017.11.22543. - URL: http://e-notabene.ru/hr/article_22543.html (data obrashcheniya: 16.05.2019).

6. Zasovenko A. Yu. Zakonnost' - osnova pravoprimenitel'noy deyatel'nosti rossiyskoy politsii / Gosudarstvo i pravo: evolyutsiya, sovremennoye sostoyaniye, perspektivy razvitiya (navstrechu 300-letiyu politsii) : materialy XIV Mezhdunarodnoy nauchno-teoreticheskoy konferentsii. SanktPeterburg, 27-28 aprelya 2017 g. / pod red. N. S. Nizhnik: V 2 t. - T. II. - SPb.: Izd-vo SPb un-ta MVD Rossii, 2017. - S. 59-61.

7. Nikiforova S. A. E. N. Berendts o statuse politsii v politseyskom i pravovom gosudarstve // Genesis: istoricheskiye issledovaniya. - 2016. - № 6. - S. 149-161. - DOI: 10.7256/2409868X.2016.6.21066. - URL: http://e-notabene.ru/hr/article_21066.html (data obrashcheniya: 16.05.2019).

8. Nizhnik N. S. Vzaimootnosheniya vlasti, obshchestva i lichnosti kak predmet politseyskopravovoy teorii / Rossiyskaya politsiya: tri veka sluzheniya Otechestvu [Elektronnyy resurs] : materialy yubileynoy Mezhdunarodnoy nauchnoy konferentsii, posvyashchonnoy 300-letiyu rossiyskoy politsii. Sankt-Peterburg, 23-25 aprelya 2018 g. / pod red. N. S. Nizhnik. Elektronnyye dan. (19,6 Mb). - Sankt-Peterburg: Sankt-Peterburgskiy universitet MVD Rossii, 2018. - S. 239-250.

9. Nizhnik N. S. Zakonnost': plyuralizm podkhodov k rassmotreniyu sotsioyuridicheskogo fenomena v sovremennoy yuridicheskoy nauke // Vestnik Kyrgyzsko-Rossiyskogo slavyanskogo universiteta. - 2014. - T 14. - № 12. - S. 30-34. 
10. Nizhnik N. S. Omnipotentsiya politseyskogo gosudarstva v otsenke rossiyskoy politseistiki // Genesis: istoricheskiye issledovaniya. - 2017. - № 11. - S. 67-86.

11. Nizhnik N. S. Sotsioyuridicheskiy fenomen «zakonnost'» v usloviyakh dialoga nauchnykh paradigm v sovremennoy yurisprudentsii // Problemy prava. - 2012. - № 3. - S. 226-231.

12. Nizhnik N. S., Papyrin V. V. Zakonnost' kak sotsioyuridicheskiy fenomen. - SanktPeterburg: Sankt-Peterburgskiy universitet Gosudarstvennoy protivopozharnoy sluzhby MCHS Rossii: Asterion, 2012. - $190 \mathrm{~s}$.

13. Nizhnik N. S., Dergilova S. Yu. Gosudarstvo i pravo v teoretiko-pravovykh vozzreniyakh A. I. Yelistratova : monografiya. - Moskva: Yurlitinform, 2017. - 376 s.

14. Tarasov N. K. Gosudarstvennoye prinuzhdeniye: plyuralizm podkhodov k opredeleniyu sushchnosti / Aktual'nyye problemy prava i pravoprimenitel'noy deyatel'nosti: Materialy Vserossiyskoy nauchno-prakticheskoy konferentsii (18 maya 2018 g.) / red. kol.: Yu. V. Sapronov, T. Yu. Panteleyeva N. V. Vinnikova, A. S. Pestruilov, K. S. Smirnova, L. G. Litvyak, V. M. Paliy, M. R. Kangezov. - Krasnodar: Krasnodarskiy universitet MVD Rossii, 2018. - S. 62-66.

15. Tarasov N. K. O determinantakh obosnovaniya primeneniya mer gosudarstvennogo prinuzhdeniya politseysko-pravovoy teoriyey Rossii v kontse XIX - nachale XX veka // Trudy Akademii MVD Respubliki Tadzhikistan. - 2019. - № 1 (41). - S. 222-228.

(C) Тарасов Н. К., 2019

Статья поступила в редакцию 06.05.2019. 